7. Ito N, Tsunoda $\mathrm{T}$, Nakamura M, Iijima R, Matsuda $\mathrm{K}$, Suzuki $\mathrm{T}$, et al. Percutaneous bare Z-stent implantation as an alternative to surgery for acute aortic dissection with visceral ischemia. Catheter Cardiovasc Interv. 2003;58:101-2.

8. Yamakado K, Takeda K, Nomura Y, Kato N, Hirano T, Matsumura K, et al. Relief of mesenteric ischemia by Z-stent placement into the superior mesenteric artery compressed by the false lumen of an aortic dissection. Cardiovasc Intervent Radiol. 1998;21:66-8

9. Mossop P, Nixon I, Oakes J, Devine TJ, McLachlan CS. Immediate “total" aortic true lumen expansion in type A and B acute aortic dissection after endovascular aortic endografting and GZSD bare stenting. J Thorac Cardiovasc Surg. 2007; 134:1360-2

10. Mossop PJ, McLachlan CS, Amukotuwa SA, Nixon IK. Staged endovascular treatment for complicated type B aortic dissection. Nat Clin Pract Cardiovasc Med. 2005;2:316-21.

11. Léobon B, Roux D, Saccani S, Mugniot A, Muscari F, Glock Y, et al. Type A aortic dissection: new surgical strategy using intra-operative stenting. $J$ Thorac Cardiovasc Surg. 2006;131:482-3.

\title{
Endoprosthetic exclusion of type A aortic dissection through carotid artery
}

\author{
Patrick Ruchat, MD, ${ }^{\mathrm{a}}$ Pierre-Guy Chassot, MD, ${ }^{\mathrm{b}}$ and Elena Rizzo, MD, ${ }^{\mathrm{c}}$ Lausanne, Switzerland
}

Even today, totally endovascular repair of the ascending aorta remains only anecdotally reported, ${ }^{1}$ although $\operatorname{arch}^{2}$ and descending aorta endoprosthetic replacements are currently performed. Recognized treatment of type A dissection still remains emergency replacement of the ascending aorta, with adequate aortic valve and coronary ostial management. ${ }^{3}$ We describe a case in which the surgical strategy had to be somewhat innovative.

\section{CLINICAL SUMMARY}

A 64-year-old white man with a history of subtotal pericardiectomy for constrictive pericarditis had undergone a transseptal mechanical valve replacement 33 years previously to treat a degenerative mitral regurgitation. Because of a severe mediastinal fibrosis, we proceeded through a right anterolateral thoracotomy and right venoarterial femoral cannulation. Because of severe hemodynamic instability during cardiopulmonary bypass, arterial cannulation problems were suspected. Finally, retrograde iatrogenic aortic dissection with involvement of the ascending aorta was confirmed by transesophageal echocardiography. An attempt to replace the ascending aorta was undertaken but discontinued because of the extremely dense, fibrous tissue surrounding all cardiovascular structures. The patient's postoperative course was uneventful, with a computed tomographic (CT) scan confirming an untreated type A dissection without aortic regurgitation and with a reentry tear in the ascending aorta (Figure 1,A). The patient was

\footnotetext{
From the Departments of Cardiovascular Surgery, ${ }^{\mathrm{a}}$ Anesthesiology, ${ }^{\mathrm{b}}$ and Radiology, University Hospital, Lausanne, Switzerland.

Received for publication June 3, 2008; accepted for publication Nov 15, 2008; available ahead of print March 27, 2009.

Address for reprints: Patrick Ruchat, MD, Department of Cardiovascular Surgery, Centre Hospitalier Universitaire Vaudois, Rue du Bugnon 46, CH-1011 Lausanne,

Switzerland (E-mail: Patrick.Ruchat@chuv.ch).

J Thorac Cardiovasc Surg 2009;138:1035-7

$0022-5223 / \$ 36.00$

Copyright (c) 2009 by The American Association for Thoracic Surgery

doi:10.1016/j.jtcvs.2008.11.019
}

discharged on postoperative day 11 with adequate dosages of $\beta$-blocker and angiotensin-converting enzyme inhibitor.

Three months later, control CT scan showed a marked 9-mm increase in the aortic diameter (Figure 1, $B$ and $C$ ). The only option was an endoprosthetic repair of the ascending aorta. After consent had been obtained, a customized $44 \times 70$-mm polytetrafluoroethylene-covered endoprosthesis with distal open web (EndoFit; LeMaitre Vascular, Inc, Burlington, Mass) was inserted through a cutdown to the left common carotid artery, the only nondissected supra-aortic vessel. Good positioning of the endoprosthesis, with confirmation of tear and false-lumen exclusion, was checked by intraoperative transesophageal echocardiography. The postoperative course was clinically uneventful, with the absence of any aortic regurgitation on transthoracic echocardiography. CT scan on postoperative day 2 (Figure 2, A) revealed free coronary ostia and aortic valve commissures, with complete thrombosis of the false lumen an without endoleak. At 1-year follow-up, CT scan showed a complete repair of the aortic wall without compromise on the brachiocephalic trunk at the distal part of the prosthesis (Figure 2, $B$ and $C$ ).

\section{DISCUSSION}

Treatment of iatrogenic type A dissection is emergency replacement of the ascending aorta. ${ }^{4} \mathrm{We}$ had to consider, however, that the only available solution for our threatened patient was an endovascular procedure with remote insertion through the left common carotid artery. ${ }^{5}$ Common carotid clamping is rarely associated with brain ischemia because of collateralization through the external carotid and contralateral facial arteries. In this procedure, we monitored brain ischemia by near-infrared cerebral oximetry with the patient under general anesthesia. This technique is well correlated with clinical neurologic surveillance during carotid endarterectomy with the patient under local anesthesia. Endoprosthesis insertion into the ascending aorta to exclude 

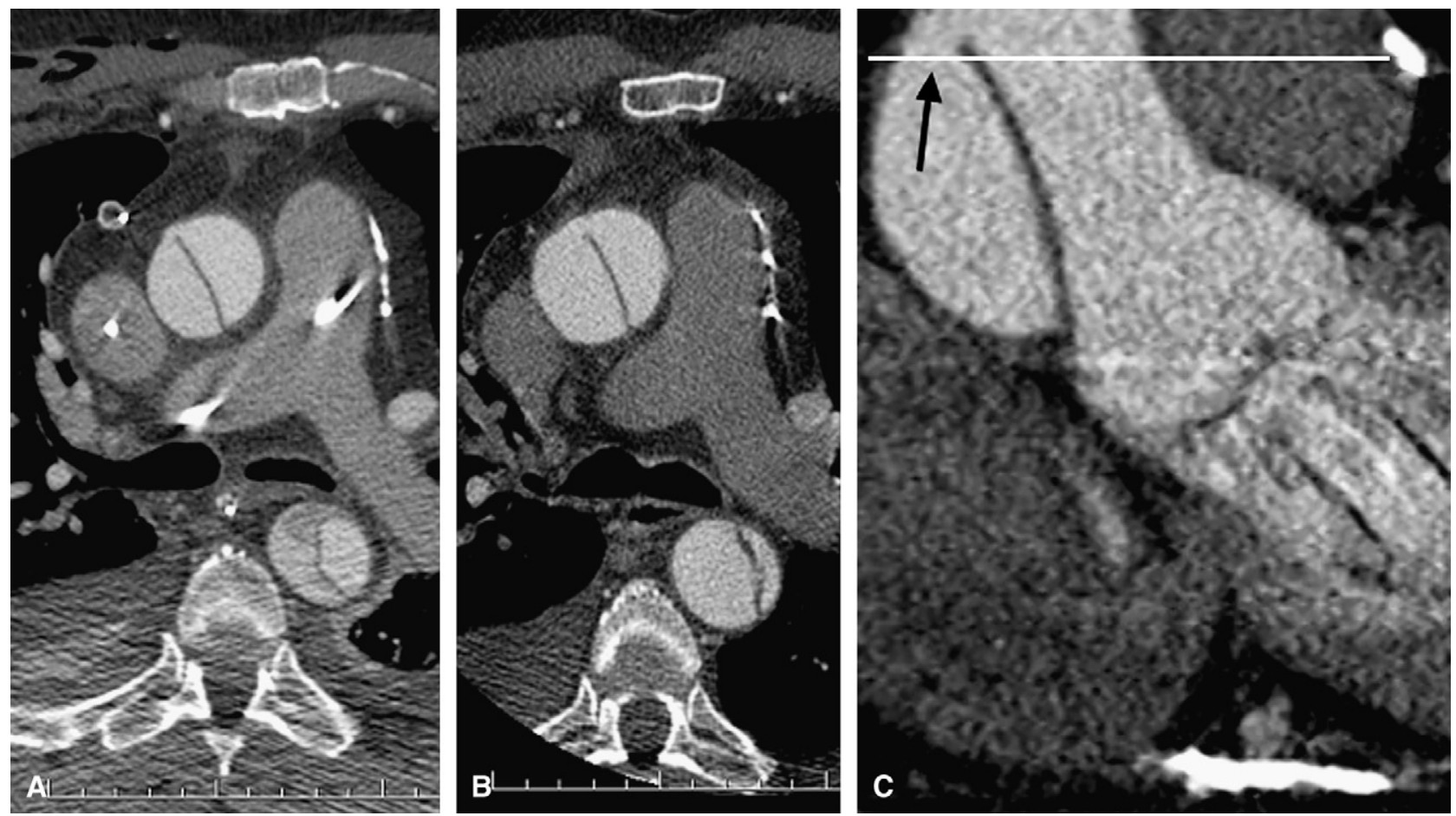

FIGURE 1. Electrocardiographically gated computed tomographic scan of dissected aorta. Immediate axial (A) and 3-month follow-up axial (B) and coronal (C) views of dissected ascending aorta. Maximal diameter of ascending aorta increased from $43 \mathrm{~mm}$ to $52 \mathrm{~mm}$ between immediate and 3-month axial scans. Presence of single reentry fenestration in membrane between false and true lumens at distal third of ascending aorta was well documented (arrow). White line defines exact level of axis view.
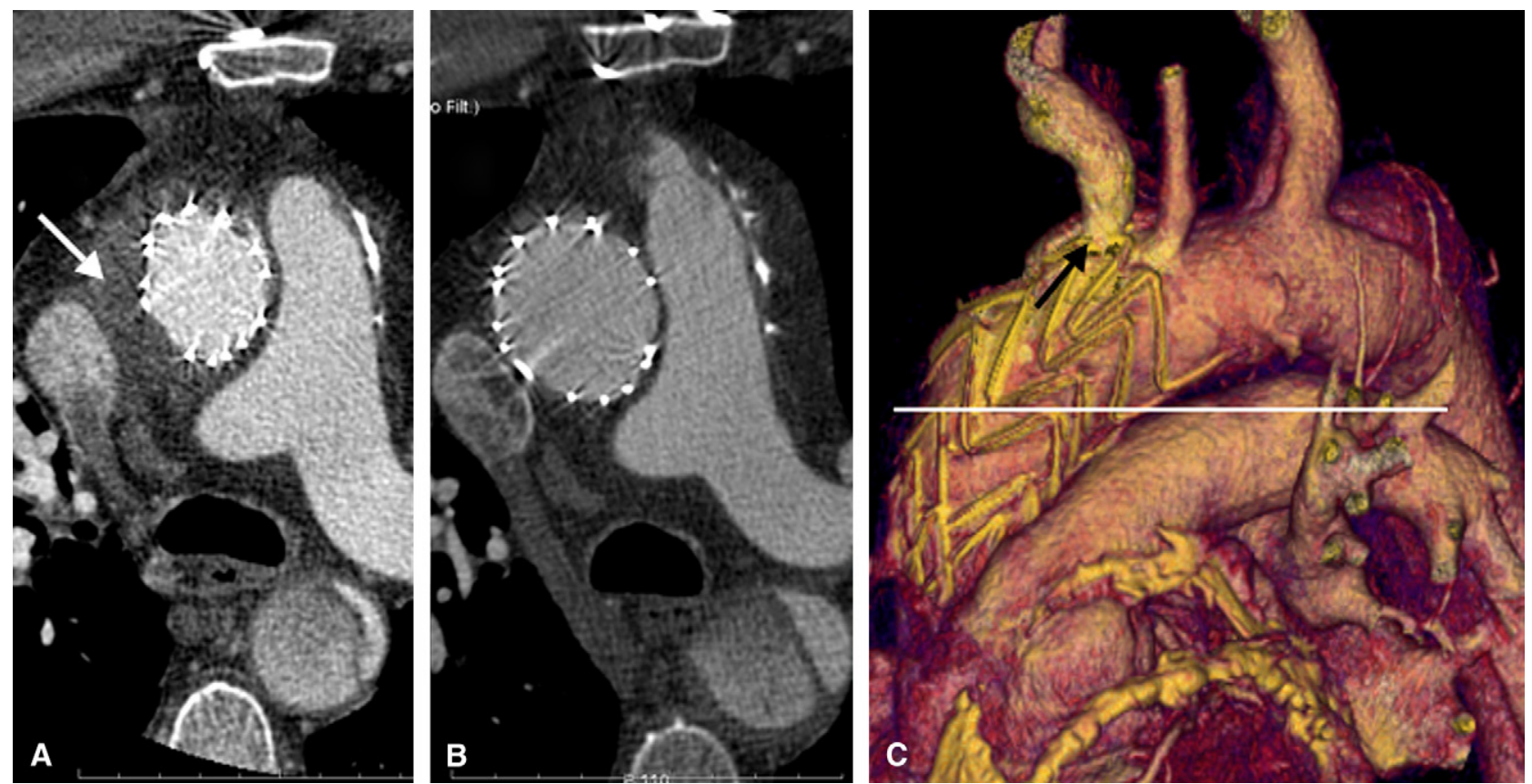

FIGURE 2. Postendoprosthetic electrocardiographically gated computed tomographic scan of aorta. Immediate axial view (A) shows still-present but thrombosed false lumen of ascending aorta (arrow). At 1-year follow-up, axial (B) and 3-dimensional (C) views reveal good sealing of endoprosthesis, with disappearance of false lumen and complete scarring of aortic wall. Brachiocephalic trunk (arrow) is well preserved, with no ostial stenosis. 
pseudoaneurysms has already been described, ${ }^{1}$ but to our knowledge this is the first description of a mandatory endovascular treatment of type A aortic dissection.

\section{References}

1. Roux D, Brouchet L, Rousseau H, Elghobary T, Glock Y, Fournial G. Treatment of a fistula at the distal anastomosis after Bentall operation with endoluminal covered stent. Ann Thorac Surg. 2002;74:2189-90.
2. Siniscalchi G, Tozzi P, Ferrari E, Delay D, Ruchat P, von Segesser L. Endovascular repair of aortic arch aneurysm after achievement of local anesthesia. $J$ Thorac Cardiovasc Surg. 2007;133:262-3.

3. Pretre R, von Segesser LK. Aortic dissection. Lancet. 1997;349:1461-4.

4. Ruchat P, Hurni M, Stumpe F, Fischer AP, von Segesser LK. Acute ascending aortic dissection complicating open heart surgery: cerebral perfusion defines the outcome. Eur J Cardiothorac Surg. 1998;14:449-52.

5. Heidenreich JH, Neschis DG, Costanza MJ, Flinn WR. Endovascular repair of a penetrating thoracic aortic ulcer by way of the carotid artery. J Vasc Surg. 2003;38:1407-10 